\title{
MÍDIA PÓS-MASSIVA: UM LEVANTAMENTO DE PODCAST ESPECIALIZADO EM MEIO AMBIENTE COMO INSTRUMENTO DE CONSCIENTIZAÇÃO AMBIENTAL
}

\author{
POST-MASSIVE MEDIA: A SURVEY OF PODCAST SPECIALIZED IN THE \\ ENVIRONMENT AS AN INSTRUMENT FOR ENVIRONMENTAL AWARENESS
}

\author{
Arantxa Carla da Silva Santos \\ Universidade da Amazônia, Brasil \\ arantxacssantos@gmail.com \\ Renata da Cruz Paes \\ Universidade do Estado do Pará, Brasil \\ contact.renatapaes@gmail.com \\ Altem Nascimento Pontes \\ Universidade do Estado do Pará, Brasil \\ altempontes@hotmail.com
}

\begin{abstract}
RESUMO: O intuito deste artigo é realizar um mapeamento dos podcasts existentes no Brasil e que são utilizados como ferramenta para disseminação de temas voltados ao meio ambiente. Para tanto, foi analisado o uso desse modelo de mídia de comunicação e o seu fator de conscientização ambiental. Em termos metodológicos, a pesquisa foi qualiquantitativa e exploratória, consistindo no levantamento de 20 podcasts de acesso gratuito e disponíveis na web. Foram contabilizados 1.189 episódios divididos desigualmente entre 20 podcasts. A partir da Análise de Conteúdo (AC), identificou-se que a maioria dos podcasts é produzido em São Paulo e surgiu no ano de 2018. Eles são publicados semanalmente e a maioria em formato de entrevista. Notou-se ainda que o tema ambiental de maior ocorrência é sustentabilidade. Apesar de esta mídia ser relativamente recente, especialmente no Brasil, os podcasts têm se disseminado e instigado debates sobre o meio ambiente, inclusive no que se refere à Amazônia, que é, entretanto, temática ainda pouco discutida nessa plataforma digital.
\end{abstract}

PALAVRAS-CHAVE: comunicação; internet; áudio; cibercultura.

\begin{abstract}
The purpose of this article is to map the podcasts that exist in Brazil and are used as a tool to disseminate themes focused on the environment. For this, the use of this communication media model and its environmental awareness factor was analyzed. In methodological terms, the research was qualitative and exploratory, consisting of the survey of 20 podcasts of free access and available on the web. There were 1,189 episodes divided unequally between 20 podcasts. Anchored in the Content Analysis, it was identified that most podcasts are produced in São Paulo and emerged in the year 2018. They are published weekly, and most of them have the content based on interviews. It was also noted that the environmental theme of greatest occurrence is sustainability. Although this media is relatively recent, especially in Brazil, podcasts have disseminated and instigated debates about the environment, including about the Amazon, but it is still little discussed in this digital platform.
\end{abstract}


KEYWORDS: communication; internet; audio; cyberculture.

\section{Introdução}

Em um primeiro momento, a palavra podcast pode gerar estranheza para quem pouco contato tem com as novas tecnologias de informação (LENHARO, CRISTOVÃO, 2016, p. 311). Para facilitar a compreensão dessa mídia, pode-se dizer que o podcast é a versão atualizada do rádio (LOPES, 2015, p. 23). A diferença é que no podcast existe a "possibilidade de descarregá-lo automaticamente para o computador ou transferi-lo a um dispositivo que lê arquivos em MP3 (Moving Picture Experts Group-1 AudioLayer 3)" (CARVALHO et al., 2018, p. 66).

A origem da palavra podcast ainda é desconhecida (MEDEIROS, 2006, p. 11), porém a versão mais divulgada e aceita se dá pela derivação dos termos broadcasting (radiofusão) e IPod (leitor digital portátil). Para Berry (2006, p. 150), a nova mídia consiste num arquivo de áudio em que os usuários podem baixar e ter em casa, além de ouvi-lo em diversos dispositivos.

De acordo com Meditsch (1999, p. 53), embora haja certa semelhança entre o podcast e o que poderia ser chamado de "rádio pela internet", já que se trata essencialmente de informações passadas via arquivos de áudio, não é esse o caso. A grande ousadia dessa nova tecnologia é a junção do conceito que se tinha de rádio com as tendências para as rádios no futuro, sobretudo com relação à comunicação horizontal, ou seja, entre emissor e receptor (FERNANDES; ALVES, 2009, p. 22).

Jesus $(2014$, p. 23) define podcast e acrescenta uma nova nomenclatura, o podcasting. Segundo ele, podcast é um arquivo de mídia transmitido via Feed RSS (Real SympleSyndication - forma de distribuição de conteúdo online). Essa transmissão recebe o nome de podcasting.

O formato mais comum é o áudio, mas isso não exclui outros formatos de mídia. Lenharo e Cristovão (2016, p. 320) classificam-no como um arquivo disponível na web para os interessados em temáticas sobre entretenimento, divulgação de informações jornalísticas e até fins educacionais.

Esse tipo de mídia permite ao usuário maior flexibilidade ao escutar o conteúdo, em horários alternados e a possibilidade de realizar multitarefas enquanto o ouve (ABDOUS; CAMARENA; FACER, 2009, p. 39). Além disso, a mídia se integra a vários ambientes virtuais como blogs, sites e outras plataformas, podendo ser produzida e disponibilizada por rádios, jornalistas, instituições de ensino, instituições de formação profissional, produtoras independentes, artistas, escolas e profissionais amadores (BONINI, 2015, p. 31).

Por existir a possibilidade de se "produzir informação, se conectar, interagir e compartilhá-la, independentemente de onde estiver, bastando apenas um dispositivo móvel e uma conexão sem fio" (VOLPATO, 2017, p. 139), os podcasts são considerados mídias pós-massivas, assim como blogs e redes sociais (LEMOS, 2004, p. 13).

Como explica Lemos (2007, p. 91), ao contrário dos veículos de massa, em geral, atrelados ao governo, controle editorial, competição por informação, as mídias pósmassivas permitem a personalização e propagação da informação sem o controle de 
empresários, Estado ou marketing.

$\mathrm{Na}$ prática, a mídia pós-massiva propõe o rompimento tradicional do fluxo de informações, em que um emite para o outro receptar. Nesse novo modelo, os receptores têm a liberdade de exercer a função de produtores, emissores e coatores de conteúdo (GONÇALVES; LOUREIRO, 2018, p. 22).

A esse fluxo contínuo de acesso e consumo proporcionados pelos meios digitais, dá-se o nome de uma cultura já convencionada, chamada de cibercultura (LEMOS, 2007, p. 102). A cibercultura se dá dentro do ciberespaço, definido por Lévy $(1999$, p. 17) como o novo meio de comunicação que surge da interconexão mundial dos computadores. Não se refere só a infraestrutura material da comunicação digital, mas também ao universo de informações que abriga, assim como os seres humanos que navegam e se alimentam desse universo.

\subsection{A gênese do podcast}

Luiz (2014, p. 102) relata que, em 2003, Dave Winer criou o enclosure. Segundo o mesmo autor, antes condicionado apenas a textos, o enclosure fez com que o RSS se estendesse para o áudio, o que possibilitou ao jornalista Cristopher Lydon disponibilizar entrevistas na internet. O enclosure, além de ampliar o compartilhamento de áudio, possibilitou o de vídeos e imagens (op. cit., p. 103).

Um ano depois, Adam Curry, empresário da MTV e considerado o pai do podcast, disponibilizou o próprio programa em áudio para os ouvintes, ao pegar um iPod e compartilhar o RSS para o agregador iTunes (SARKAR, 2012, p. 80). Essa técnica possibilitou que os demais reprodutores de áudios digitais surgissem de forma livre e os usuários fizessem download automático dos arquivos (LUIZ, 2014, p. 105).

Os sistemas que permitem acesso aos podcasts não se limitaram ao IPod, pelo contrário, houve a popularização (CARVALHO; SALDANHA, 2018). Prova disso é que hoje "grandes marcas como LG, Samsung, Nokia, Submarino e Bradesco acreditam e investem no podcast devido à visibilidade" (op. cit., p. 28).

Embora seja possível encontrar exemplos de podcasts ligados a empresas de mídia tradicional ou criados por radialistas, grande parte dos podcasts é produzida por pessoas que não necessariamente estão atreladas profissionalmente à área de Comunicação, mas sim pessoas que puramente fazem uso do seu tempo disponível para projetos pessoais relacionados à internet, entre eles, a produção de podcasts (PRIMO, 2005, p. 17).

Em teoria, para se produzir um podcast é necessário apenas um computador equipado com um microfone, fones de ouvido e uma placa de áudio com capacidade de gravação e reprodução de sons, onde basta que o usuário capture o áudio e crie um arquivo de som que posteriormente será disponibilizado na internet (MEDEIROS, 2006, p 13).

Outra característica do podcasting são os tipos de arquivo, a disponibilidade e o acesso, considerando que, uma vez que um podcast novo vai ao ar, os ouvintes precisam ser informados de que ele foi publicado de forma automática através do RSS (CARVALHO; SALDANHA, 2018; VANASSI, 2007). 
Os registros são de que o primeiro podcast no Brasil surgiu em 21 de outubro de 2004, por meio do Digital Minds, idealizado por Danilo Medeiros (CARVALHO; SALDANHA, 2018, p. 65). Não que tenha sido aí o princípio da obtenção de áudio na internet pelos usuários, mas sim o download de áudio por via podcasting.

Em 2 e 3 de dezembro de 2005 foi organizada em Curitiba, Paraná, a primeira edição da Conferência Brasileira de Podcast (PodCon Brasil), primeiro evento brasileiro destinado exclusivamente ao tema, durante o qual foi fundada a Associação Brasileira de Podcast (ABPod).

Em 2008 aconteceu a primeira edição da PodPesquisa, a primeira ação voltada a analisar o perfil dos ouvintes brasileiros de podcast. A pesquisa contou com 436 respostas e foi realizada novamente em 2009, quando obteve 2.487 questionários válidos (LUIZ; ASSIS, 2009, p. 163). Ela ocorreu novamente em 2014, alcançando 16.197 respostas válidas (ABPOD, 2014) e mais recentemente em 2018.

"A quantidade de sobreviventes da primeira geração brasileira foi muito baixa, mas felizmente, em 2006, novos foram criados e houve maior crescimento, principalmente em 2008, com a adição da categoria Podcast no prêmio iBest" (LUIZ, 2014, p. 11). Mesmo em meio às novidades que essa mídia trouxe, em 2015 ocorreu o fim de inúmeros podcasts no Brasil.

Apesar disso, a mídia está em constante crescimento, de acordo com dados da PodPesquisa, realizada pela ABPod, em 2018. Através de questionário aplicado com 22.993 pessoas, identificou-se que 22.691 pessoas são ouvintes de podcast no Brasil; dentre os quais 1.405 se apresentaram também como produtores de podcast.

Entre os ouvintes, a maioria está entre 30 e 39 anos $(31,4 \%)$, possui ensino superior completo $(32,7 \%)$, é residente do estado de São Paulo (36,6\%), ouve podcast todos os dias $(51,1 \%)$, ouve somente podcasts nacionais $(62,0 \%)$, opina que a frequência de publicação deveria ser semanal $(80,5 \%)$, os formatos de maior interesse são debates $(75,0 \%)$ e entrevista (55,5\%), acompanha cinco podcasts simultaneamente $(11,1 \%)$, considera o conteúdo o fator mais importante $(94,2 \%)$ e ouve a mídia com o intuito de entretenimento $(87,7 \%)$.

Entre os produtores, a faixa etária é de 30 a 39 anos (42,5\%), possuem ensino superior completo $(37,4 \%)$, moram no estado de São Paulo $(43,4 \%)$, a maioria começou a produzir podcast em 2018 (27,0\%), produz somente um podcast (71,2\%) e publica um episódio por semana $(32,0 \%)$.

\subsection{Podcast como conscientizador ambiental}

As funções do podcast são variadas, desde o entretenimento e a divulgação de informações até o seu uso para fins educacionais. Nos dias de hoje, é um modo de publicação muito utilizado por diversas pessoas e empresas ao redor do mundo para divulgar materiais diversificados, assim como é utilizado por universidades, que disponibilizam aulas nesse formato. Embora relativamente nova, o podcast é uma tecnologia já bastante difundida, inclusive no Brasil, onde são produzidos podcasts sobre os mais variados temas (LENHARO; CRISTOVÃO, 2016, p. 311).

A partir da Conferência das Nações Unidas sobre Meio Ambiente, sediada no Rio 
de Janeiro, em 1992, a população e a mídia se atentaram mais para o aumento da crise ecológica (CAMPOS, 2006, p. 46). Todavia, Alves (2002, p. 18) diz que depois desse período, o meio ambiente só virou notícia diante de catástrofes ambientais e cenas fortes.

Aranha et al. (2016, p. 179) relatam que, em 2015, a partir de uma pesquisa feita com 135 alunos de um cursinho popular da cidade de Bauru (SP), identificou-se que $98,0 \%$ dos jovens declararam não ter acesso a informações ambientais especializadas sobre meio ambiente. Isso indica preocupação, visto que, de acordo com a Pesquisa Brasileira de Mídia 2015, 65,0\% dos jovens (16 a 25 anos) brasileiros acessam diariamente a internet.

Os estudos de Fidalgo (2009, p. 16) reforçam que as novas audiências se direcionaram às atuais fontes de informação, aos dispositivos móveis e às mídias sociais. Apesar disso, na Amazônia, região de grande extensão territorial (PONTE; LIMA; RODRIGUES, 2018, p. 89), responsável por $60,0 \%$ de todo o percurso hidroviário do Brasil (ANA-MMA, 2005), ainda se encontram dificuldades de comunicação, desde o acesso limitado à internet até o telefone (OLIVEIRA, 2013, p. 152).

Apesar disso, é inegável o grande volume de informação produzida pelos diversos podcasts existentes, muitos dos quais dedicados a nichos que não encontram espaço na mídia tradicional. Contudo, existem podcasts voltados exclusivamente à divulgação de notícias, tanto gerais quanto de temas específicos ou de nicho. Segundo Primo (2005, p. 62), nesses casos os podcasters costumam comentar notícias publicadas na mídia tradicional ou até em portais da internet, ampliando seu alcance, mas com o risco de gerar a mera reprodução do discurso da grande mídia.

Num mundo globalizado onde temos cada vez menos tempo para aceder à informação e ao conhecimento, o podcast surge como uma alternativa viável, prática, com custos quase nulos e também uma metodologia de ensino-aprendizagem bastante motivadora, se tornando uma ferramenta de disseminação de variadas temáticas, incluindo a ambiental (BOTTENTUIT JUNIOR; COUTINHO, 2007, p. 112).

Assim sendo, a presente pesquisa teve como objetivo fazer um levantamento da quantidade de podcasts disponíveis na web, voltados à temática ambiental no Brasil, assim como propor o uso desta mídia para divulgação e debates de temas para conscientização ambiental.

Portanto, questiona-se: quais as temáticas mais presentes nos podcasts ambientais? Quantos temas se voltam à Amazônia? Quantas plataformas na web produzem esse tipo de conteúdo, no Brasil? Qual a origem dessas plataformas? Com que frequência os conteúdos são publicados?

\section{Metodologia}

A princípio fez-se um mapeamento dos programas mais populares, em sites de busca e em sites e/ou aplicativos de celular especializados na divulgação de podcasts com temática ambiental, disponíveis gratuitamente na Web.

Para a busca, foram utilizadas as palavras-chave "podcast sobre meio ambiente", "podcast sobre natureza", "podcast sobre sustentabilidade", de modo a facilitar a obtenção dos dados. Após varredura, foram encontrados 20 podcasts com temáticas ambientais. 
Posteriormente, realizou-se análise do conteúdo (BARDIN, 2011, p. 182) dos podcasts a partir da categorização. Segundo Bardin (2011, p. 183), a categorização é um dos procedimentos da análise de conteúdo e consiste em uma classificação de elementos com um título genérico que possibilita a transformação de dados brutos em organizados.

Analisou-se, então, o nome do podcast; o período de sua estreia, entendida pelo mês e ano da sua primeira publicação; a periodicidade da publicação de episódios (semanal, quinzenal ou mensal); o número de episódios disponíveis para download (contabilizada até a realização desta pesquisa); se o podcast ainda está ativo, ou seja, se publicou novos episódios nos seis meses retroativos a esta pesquisa; o formato do seu respectivo conteúdo; o lugar de origem ou sede do podcast; e, por fim, os três temas mais abordados ao longo dos episódios.

Para o formato, considerou-se a definição feita por Filho (2003, p. 15), que classificou os gêneros radiofônicos, referência que foi indicada por levar em conta a inspiração que muitos podcasts obtêm dos programas de rádio convencionais.

De acordo com Filho (2003), os gêneros radiofônicos podem ser caracterizados em: Jornalístico (nota, notícia, boletim, reportagem, entrevista, comentário, editorial, crônica, documentário jornalístico, mesas-redondas ou debates, programa policial, programas desportivos e de divulgação tecno-científica); Educativo-Cultural (autobiografia, documentário educativo-cultural, programa temático); Entretenimento (programa musical, ficcional e evento artístico); Publicitário (spot, jingle, testemunhal, peça de promoção); Propagandístico (peça radiofônica de ação pública, programas eleitorais e religiosos); Serviço (notas de utilidade pública, e de serviço); Especial (programa infantil, programa de variedades).

Dessa maneira, a investigação gerou dados referentes aos 20 podcasts (sites/feeds) sobre meio ambiente selecionados de forma intencional, na qual, segundo Duarte (2006, p. 68), o pesquisador faz a seleção por juízo particular, com o conhecimento do tema ou representatividade subjetiva. Por isso, foram considerados apenas podcasts produzidos por brasileiros cujo público-alvo também é formado por brasileiros, que, então, foram analisados e caracterizados para, a seguir, originar a discussão dos resultados.

\section{Resultados e discussão}

Para a análise, contabilizou-se o número de episódios de cada podcast estudado, chegando aos seguintes dados: Vozes do Planeta (273), Minuto da Terra (149), Meio Ambiente (130), Pensando Verde (125), Cidades Sustentáveis (89), Ecopolítica (89), Mundo Sustentável (65), Aquecimento Verbal (60), Apenã (36), Agro em Cinco Minutos (26), Planeta Sustentável (26), Eco-Evolução (22), Rotas Alternativas (21), Reflexões sobre Sustentabilidade (18), Eficiencialidade (12), Impacto Positivo (12), Desabraçando Árvores (9), As Árvores Somos Nozes (8), FloresCast (8), VerdeCast (8), Janela Verde (3), conforme apresenta o Gráfico 1. 


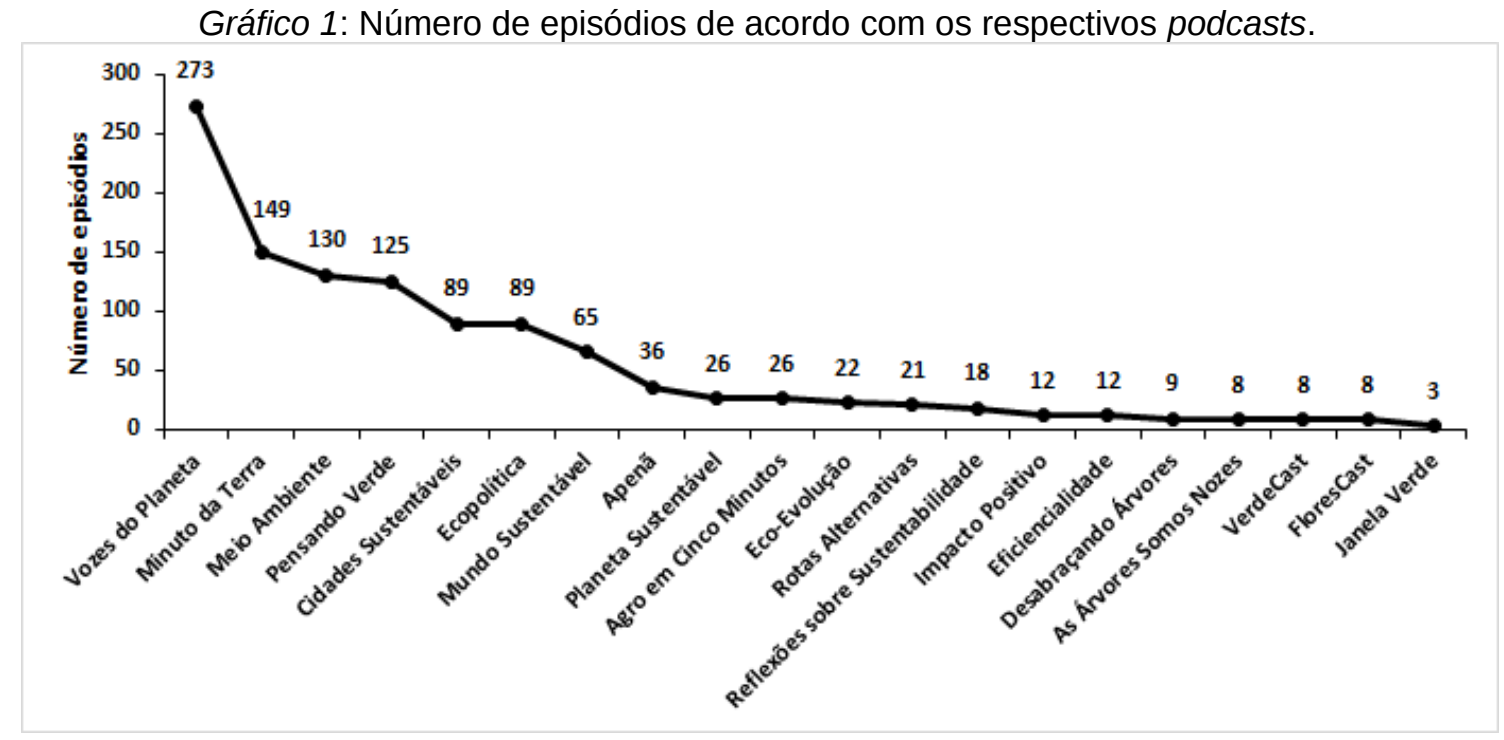

Fonte: Pesquisa de campo.

O podcast "Vozes do Planeta" foi o que mais obteve conteúdos postados (273). Ele se trata de uma produção contínua, que recebe atualizações de conteúdo constantemente, a partir de pautas do momento, como "Carnaval Sustentável" e "Especial Brumadinho". Os conteúdos produzidos são um meio de difusão de entrevistas e debates com especialistas na área, que podem levar até mais de uma hora de áudio, e, portanto, trazer conteúdo jornalístico ambiental aprofundado ao leitor.

Assim como o "Vozes do Planeta", o podcast "Minuto da Terra" também possui frequência constante de publicação. O diferencial é que o "Minuto da Terra" busca, em menos de cinco minutos, ensinar sobre as questões ambientais, ao envolver ciência e história com entretenimento.

Com esse tipo de conteúdo, a informação se torna mais atraente a um público menos especializado, jovem, que busca diversão. Os conteúdos também são de curta duração, o que, segundo Cruz (2009, p. 79), diminui a possibilidade de abandoná-los.

Para Jenkins (2010, p. 41), a convergência das mídias tradicionais para as digitais altera a lógica pela qual a indústria midiática opera e pela qual os consumidores processam a notícia e o entretenimento.

Apenas o terceiro podcast "Meio Ambiente" é o que traz no nome implicitamente a ideia central da temática ambiental. Foram 130 podcasts publicados frequentemente. Assim como o "Vozes do Planeta", o "Meio Ambiente" trata-se de podcasts em formato de entrevistas. O diferencial é que o conteúdo é de origem francesa, mas apresentado em português. Portanto, traz temáticas ambientais tanto da realidade brasileira quanto estrangeira, fazendo um paralelo entre a realidade ambiental dos dois países.

Com essa mescla de informação brasileira e francesa na mesma página, pode ocasionar de os discursos estrangeiros ofuscarem as fontes da identidade ambiental do Brasil, conforme defende Pratt (1999). Assim, os conteúdos deixam de ser locais para se tornarem globais e as realidades ambientais no Brasil podem não ser as mesmas da França.

O Gráfico 2 apresenta o ano de estreia dos podcasts, caracterizado pelo 
surgimento de nove podcasts em 2018 (45\%), dois em 2017 (10\%), sete em 2016 (35\%), um em 2013 (5\%) e um em 2011 (5\%). Também se analisou a periodicidade dos podcasts. Destes, 12 constam como publicação semanal (60\%), três quinzenal (15\%) e cinco mensal (25\%).

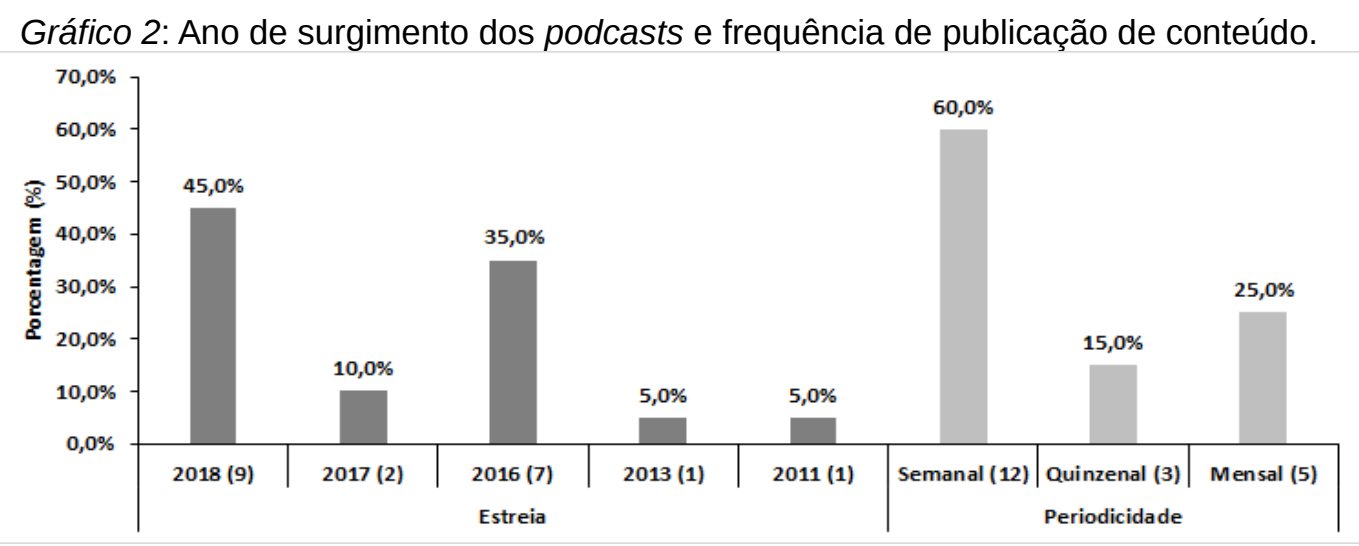

Fonte: Pesquisa de campo.

Notou-se que em 2018 surgiu um número maior de podcasts especializados na temática ambiental. De acordo com os assuntos das primeiras postagens, percebeu-se 0 interesse em abordar o desenvolvimento de cidades sustentáveis, com projetos arquitetônicos e divulgação de eventos de mercado de construção verde.

Percebeu-se ainda em 2018, no surgimento dos podcasts, conteúdos voltados à ideia de desenvolvimento sustentável aliado ao desenvolvimento econômico e uma vida urbana ambientalmente sustentável e economicamente mais rentável.

As publicações, aparentemente, enfatizam o discurso presente na sociedade de que a equidade social e ambiental se relaciona com investimento econômico, ao criar alternativas sustentáveis, a partir do comportamento humano, hábitos de consumo e produção (VEIGA, 2005, p. 16).

Notou-se ainda que os podcasts "As Árvores Somos Nozes" e "Agro em Cinco Minutos" surgiram no final de 2018, em meio às eleições para o novo presidente do Brasil. Um dos candidatos e posteriormente eleito à presidência, Jair Bolsonaro, trouxe questões polêmicas quanto a demarcação das áreas indígenas e flexibilização das licenças ambientais. Os podcasts trouxeram tais discussões em pauta.

O ano de 2016 também revelou um número maior de criação de podcasts. As temáticas que iniciaram as publicações também continham a ideia de desenvolvimento urbano por meio de cidades sustentáveis. O diferencial desse ano foi o ensino de ciência e temáticas educativas por meio de podcasts.

Para Botton, Peripolli e Santos (2017, p. 2), como ferramenta de educação, o podcast possibilita suscitar a autonomia do pensamento e ação dos alunos, motivando-os para a pesquisa não somente no contexto de sala de aula.

O Gráfico 3 mostra os podcasts ativos e inativos e seus respectivos lugares de origem. Percebeu-se que $60,0 \%$ dos conteúdos levantados nesta pesquisa estão ativos e $40,0 \%$ inativos. O fato de quase metade de os podcasts não terem dado continuidade 


\section{chama atenção.}

Segundo Lopes (2015, p. 70), os motivos que fazem as produções descontinuarem está na falta de domínio das ferramentas de edição de áudio, assim como a necessária produção de uma pauta para guiar o programa, baixa audiência e elevada concorrência com grandes veículos de informação jornalística.

Gráfico 3: Número de podcasts em atividades e os respectivos lugares de origem das produções.

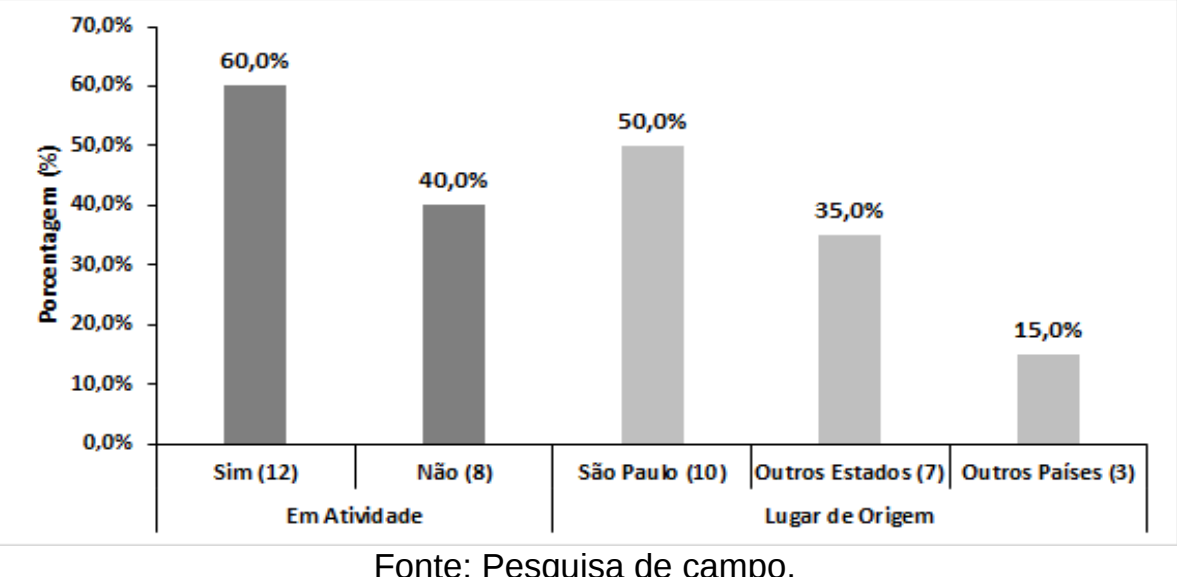

Fonte: Pesquisa de campo.

Quanto ao local de origem da produção dos conteúdos, identificou-se que 50,0\% (10) dos podcasts são produzidos em São Paulo (SP), 35,0\% (7) em outros estados do Brasil e 15,0\% (3) em outros países. De acordo com Dalmolin e Silveira $(2016$, p. 32), grande parte dos veículos de comunicação estão localizados no eixo Rio-São Paulo. Portanto, haverá uma maior concentração e produção de conteúdo nessa região.

O Gráfico 4 apresenta os formatos dos podcasts. Entre os investigados, seis possuem o formato de entrevista (30,0\%), contando com a presença de especialistas e profissionais da área ambiental, três possuem o formato de debate $(15,0 \%)$, três se caracterizam como programa temático $(15,0 \%)$, três são de formato de comentário $(15,0 \%)$, dois se caracterizam como boletim $(10,0 \%)$ e três se definem em outros formatos $(15,0 \%)$.

Gráfico 4: Principais formatos dos podcasts.

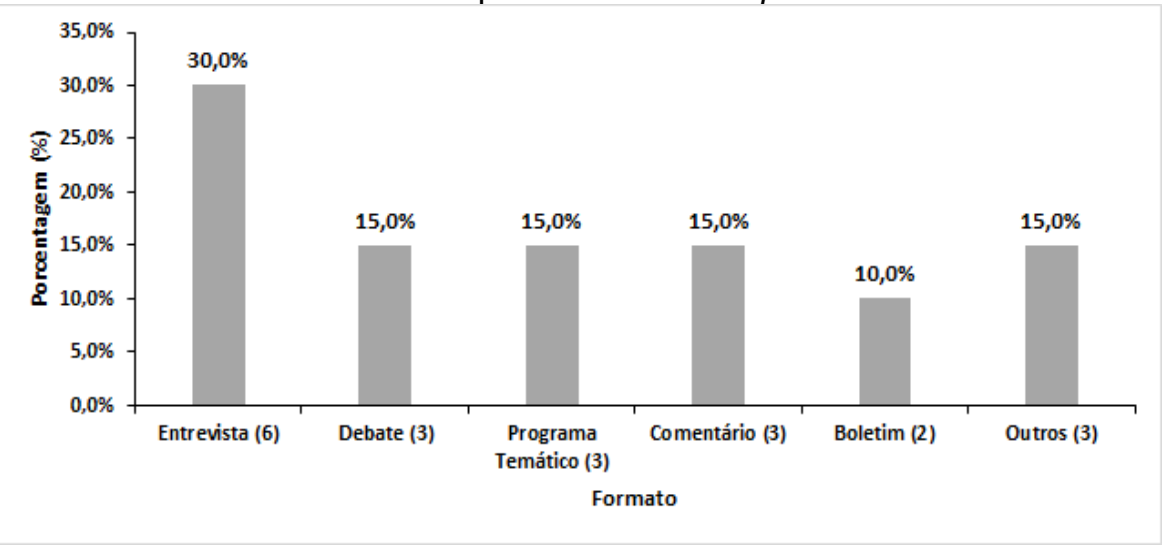

Fonte: Pesquisa de campo. 
O formato jornalístico de entrevista imperou entre os podcasts analisados. É válido ressaltar que o jornalismo contribuiu para o boom dessa ferramenta digital, quando o jornal Daily Telegraph, no Reino Unido, lançou um podcast diário em 2005 (BONINI, 2015, p. 27). A partir de março de 2006, "o jornal britânico The Guardian lançou 23 canais de podcast especializados em temáticas da atualidade" (REIS, 2018, p. 211).

Por meio do Gráfico 5, buscou-se ainda identificar os principais temas abordados. Totalizaram-se 60 diferentes tópicos. Os de maior ocorrência foram: sustentabilidade $(16,7 \%)$, biodiversidade $(13,3 \%)$ e educação ambiental $(11,7 \%)$, seguidos por impactos ambientais $(10,0 \%)$, políticas públicas $(10,0 \%)$, resíduos $(8,3 \%)$, desmatamento $(6,7 \%)$, energia $(6,7 \%)$, mudanças climáticas $(5,0 \%)$, recursos naturais $(2,0 \%)$ e outros temas $(8,3 \%)$.

Gráfico 5: Temas mais abordados nos podcasts.

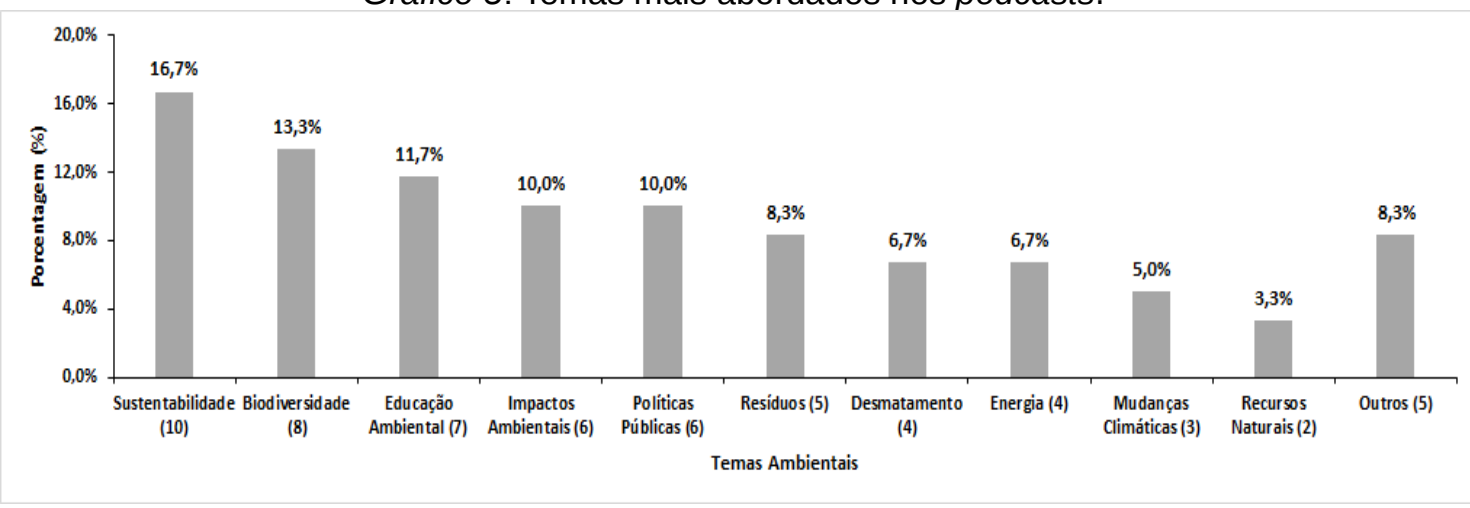

Fonte: Pesquisa de campo.

A temática da "Sustentabilidade" ganhou destaque nos podcasts. Há de se considerar o crescente discurso presente na sociedade sobre a sustentabilidade nos negócios, nas cidades, nas empresas, advindo da racionalidade econômica (LIMA, 2003, p. 90).

O discurso da sustentabilidade tem sido propagado, ora como forma de melhorar a imagem de uma empresa diante à exploração causada ao meio ambiente, ora para incentivar o consumo que, supostamente, não degrade o meio ambiente.

Entretanto, Leff (2009, p. 12) ressalta que a ideia de sustentabilidade e desenvolvimento sustentável emergiram da necessidade de superar a diferença radical que o sistema capitalista causou entre as atividades humanas, econômicas e dos sistemas naturais. Para Castro (2014, p. 88), a sustentabilidade se define pela hegemonia do desenvolvimento econômico.

As temáticas menos presentes são as que se relacionam com a floresta amazônica como "Desmatamento", sendo a região mais desmatada do Brasil (CARVALHO; MAGALHÃES, 2016, p. 77); "Energia", o berço das grandes barragens (FEARNSIDE, 2015, p. 175); e "Recursos Naturais", reconhecida como região rica em diversidade na fauna e na flora (STROPPER, 2014, p. 20).

Durante a pesquisa, encontrou-se somente um podcast de origem na região amazônica, mais especificamente no estado do Pará, o que explicita a quantidade reduzida de conteúdos mais diretamente relacionados à região. 


\section{Considerações finais}

O podcast, mesmo sendo uma mídia recente no Brasil, enfrenta muitos desafios para se concretizar, desde tempo para sua gravação e produção/edição, investimento financeiro para arcar com os gastos, estrutura de captação de áudio para garantir a qualidade do podcast, além de divulgação.

Além disso, alguns fatores influenciam os temas abordados, desde o interesse do público-alvo, a relevância do tema e a facilidade em abordar a questão, incluindo a disponibilidade de especialista da área, em especial no que se refere ao meio ambiente.

Em vista de tal pluralidade, as demandas dos podcasts tecnicamente mais preparados constituem-se, em geral, das seguintes ações: levantamento de pauta; realização de pesquisa sobre o tema a ser abordado; gravação; edição; elaboração do texto síntese da postagem; montagem de imagens para ilustrar as postagens dos programas; reunião de links relativos aos temas abordados; organização das discussões via comentários e sessão de opinião aos ouvintes; e gerenciamento técnico da distribuição dos arquivos digitais nos servidores (FREIRE, 2015, p. 1041).

É preciso ressalvar que as necessidades apresentadas se relacionam a podcasts possuidores de maior sofisticação técnica. Portanto, de modo algum se ponderam todos esses fatores como imprescindíveis para a concretização de podcasts.

O podcast é uma mídia muito nova e ainda pouco explorada, pois desde seu surgimento em 2004 muito foi feito, mas pouco foi estudado. São poucas as pesquisas acadêmicas que se dedicam a esse tema, mas mesmo assim são várias suas possibilidades.

Pode-se não só pensar a aplicação do podcast na área de comunicação, como também aplicações para a divulgação de informações e conceitos voltados para o meio ambiente, sendo uma importante ferramenta de conscientização ambiental. Especialmente, sob o ponto de vista brasileiro e com foco na Amazônia, sua biodiversidade e preservação, com base no desenvolvimento sustentável.

As possibilidades de podcasts são diversas, assim como os campos de pesquisa e estudo, levando em conta a diversidade de podcasts existentes. Dessa forma, ao analisar o futuro do podcast no Brasil, por ser uma mídia ainda pouco conhecida por grande parte da população, é preciso considerar os desafios financeiros e estruturais enfrentados pelos produtores para produzir os arquivos sonoros, desde a pesquisa até a divulgação.

Fatores ainda mais significativos quando o podcast tem objetivo para além do entretenimento, abarcando também a possibilidade de ser uma ferramenta de educação e fonte de informações que precisam ser verídicas e com referências comprovadas.

O podcast é considerado a mídia do futuro, e vem ganhando muita força no meio da comunicação. Dessa maneira, esta pesquisa não pretende solucionar nenhum grande problema, mas somente apontar possíveis caminhos por onde essas pesquisas sobre podcasts podem seguir. Ademais, ela atua como base em futuras pesquisas acadêmicas sobre podcasts, principalmente voltadas para a temática ambiental, que cresce cada vez mais ao gerar interesse público em meio aos receios principalmente sobre as mudanças climáticas, escassez de recursos e eficiência energética. 


\section{Referências}

ABDOUS, M.; CAMARENA, M.; FACER, B. R. Tecnologia MALL: uso do podcast acadêmico na sala de aula de língua estrangeira, 2009.

ABRAHÃO, J. Cidades Sustentáveis. Podcast. Disponível em: https://audioglobo.globo.com/cbn/podcast/feed/435/cidades-sustentaveis-jorge-abraao.

Acesso em: mar. 2019.

ABRANCHES, S. Ecopolítica. Podcast. Disponível: https://audioglobo.globo.com/cbn/podcast/feed/124/ecopolitica. Acesso em: mar. 2019.

AGÊNCIA NACIONAL DE ÁGUAS, Ministério do Meio Ambiente (ANA-MMA). $A$ navegação interior e sua interface com o setor de recursos hídricos. Brasília-DF: ANAMMA, mai. 2005. Disponível em: https://arquivos.ana.gov.brl. Acesso em: 30 dez. 2018.

ALVES, A. Os Desafios do Jornalismo Ambiental. 03 out. 2002. Disponível em: http://www.jornalistaambiental.jex.com.br/artigos/os+desafios+do+Jornalismo+ambiental. Acesso em: 7 fev. 2019.

APENÃ. Apenã - Pensando o amanhã. Podcast. Disponível em: http://apenan.com.br. Acesso em: mar. 2019.

ARANHA, A. S.; CRUZ, A. S. G.; SALHANI, J.; CARDINALLI; M. A. A Educomunicação Ambiental como Caminho para a Formação Cidadã. In: MACHADO, S.; SOARES, I. O.; ROSA; R. (org.). Educomunicação e diversidade: múltiplas abordagens. São Paulo, ABPEducom, 2016. [Recurso-eletrônico]. Disponível em: https://issuu.com/abpeducom/docs/ebook___educomunicacao_e_diversidad. Acesso em: 27 set. 2018.

ASSOCIAÇÃO BRASILEIRA DE PODCASTERS. PodPesquisa 2014.São Paulo: ABPod, 2014. Disponível em: http://abpod.com.br/podpesquisa_old/podpesquisa-2014.

BARDIN, L. Análise de Conteúdo. Lisboa: Edições 70, 2011.

BERRY, R. Will the iPod killthe radio star? In: CRISELL, A. Radio, critical concepts in Media and Cultural Studies. vol III, UK: Routledge, 2006. p. 143-162.

BONINI, T. The "second age" ofpodcasting: reframingpodcasting as a new digital massmedium. Quadernsdelcac, 41 XVIII, p. 23-33, 2015.

BOTTENTUIT JUNIOR, J.; COUTINHO, C. P. Qualitylndicators for theProductionand Assessment of Podcasts' Episodes. In: FERMOSO GARCIA, A.; PEDRERO ESTEBAN, A. (ed.). SPDECE 08: Actasdel V Simposio Pluridisciplinar sobre Diseño y Evaluación de Contenidos Educativos Reutilizables, 2007. s/p.

BOTTON, L. A; PERIPOLLI, P. Z.; SANTOS, L. M. A. Podcast-uma ferramenta sob a ótica 
dos recursos educacionais abertos: apoio ao conhecimento. Redin-Revista Educacional Interdisciplinar, v. 6, n. 1, 2017.

CAMPOS, P. C. Jornalismo e meio Ambiente: mídia e a consciência da sustentabilidade. Observatório da Imprensa, 17 abr. 2006. Disponível em: http://observatoriodaimprensa.com.br/artigos.asp?cod=377DAC002. Acesso em: mar. 2019.

CAPELLARI, A. C. Agro em Cinco Minutos. Podcast. Disponível em: https://soundcloud.com/agroemcincominutos. Acesso em: mar. 2019.

CAPIBARIBE, Á. Reflexões sobre Sustentabilidade. Podcast. Disponível em: https://soundcloud.com/avila-capibaribe. Acesso em: mar. 2019.

CARVALHO, F. B. da C. M. de et al. Uso de recursos podcast e webquest no estudo do tema avaliação na educação infantil. Texto Livre: Linguagem e Tecnologia, [S.I.], v. 11, n. 2, p. 192-205, jul. 2018. Disponível em: http://www.periodicos.letras.ufmg.br/index.php/textolivre/article/view/12499/1125611619. Acesso em: 13 abr. 2019.

CARVALHO, K. M. A.; SALDANHA, G. S. O som que o documento tem: o podcast da web 2.0 ao princípio monográfico. Brazilian Journal of Information Science: research trends, v. 12, n. 1, p. 36-45, 2018.

CARVAlHo, T. S.; MAGALHÃES, A. S.; DOMinguES, E. P. Desmatamento e a contribuição econômica da floresta na Amazônia. Estudos Econômicos, São Paulo, v. 46, n. 2, p. 499-531, 2016.

CASTRO, C. J. Sustainable development: mainstream and critical perspectives. Organization\&Environment, v. 17, n. 2, jun. 2004, p. 195-225, 2014.

CRUZ, S. O podcast no ensino básico. In: CARVALHO, A. A. (org.). Actas do Encontro sobre Podcasts. Braga: CIEd, 2009, p. 65-80.

DALMOLIN, A. R.; SILVEIRA, A. C. M. Um abismo vigiado: segurança e soberania no discurso jornalístico televisual sobre fronteiras na Amazônia. Revista Internacional de CienciasSociales, v. 5 , n. 1, p. 29-41, 2016. Disponível em: http://journals.epistemopolis.org/index.php/csociales/article/view/368/27. Acesso em: 11 jun. 2018.

DESABRACE. Desabraçando Árvores. Podcast. Disponível em: https://www.desabrace.com.br. Acesso em: mar. 2019.

DIÁRIO DO VERDE. VerdeCast. Podcast. Disponível em: http://diariodoverde.com/diario/verdecast. Acesso em: mar. 2019.

DUARTE, J. Entrevista em profundidade. In: DUARTE, J.; BARROS, A. (org.). Métodos e 
Técnicas de Pesquisa em Comunicação. Editora Atlas: São Paulo, 2006.

FEARNSIDE, P. M. Hidrelétricas na Amazônia: impactos ambientais e sociais na tomada de decisões sobre grandes obras. Manaus: Editora do INPA, v. 1, p. 296, 2015.

FERNANDES, J. S.; ALVES, M. D. S. Como os Podcasts podem Auxiliar a Competência Auditiva no Âmbito Ensino-Aprendizagem de Espanhol como Segunda Língua?. HOLOS, [S.I.], v. 3, p. 201-206, jan. 2009.

FIDALGO, J. M. O Lugar da Ética e da Auto-Regulação na Identidade Profissional dos Jornalistas. Tese de doutoramento, Braga, Instituto de Ciências Sociais, Universidade do Minho, 2009.

FILHO, A. B. Gênero radiofônicos - Os formatos e os programas em áudio. São Paulo: Paulinas, 2003.

FLORESTA BRASIL. FloresCast. Podcast. Disponível em: http://www.podcastgarden.com/podcast/florescast. Acesso em: fev. 2019.

FREIRE, E. P. A. Potenciais cooperativos do podcast escolar por uma perspectiva freinetiana. Revista Brasileira de Educação. Rio de Janeiro, v. 20 n. 63 out.-dez. 2015.

GONÇALVES, E. C.; LOUREIRO, R. Discursos sobre gênero na publicidade pós-massiva: um estudo do videocase "badass" à luz da semiótica sincrética discourseaboutgender in post-massiveadvertising: a studyofthe "badass" videochasethroughsyncreticsemiotics. Acta Semiótica et Lingvistica, v. 22, n. 2, 2018.

GREENPEACE. As Árvores Somos Nozes. Podcast. Disponível em: https://www.greenpeace.org/brasil/participe/podcast/. Acesso em: mar. 2018.

JENKINS, H. Cultura da Convergência. 2a edição. São Paulo. Aleph, 2010.

JESUS, W. B. de. Podcast e educação: um estudo de caso. Universidade Estadual Paulista, Instituto de Biociências de Rio Claro, 2014. 56 f. Dissertação (Mestrado), 2014.

LEFF, E. Saber ambiental: sustentabilidade, racionalidade, complexidade, poder. 7. ed. Petrópolis: Vozes, 2009.

LEMOS, A. Cibercultura e Mobilidade. In: LEMOS, A. (org). ComunicacionesMóviles. In: Razón y Palabra, n. 41, Octubre/Noviembre 2004. México.

LEMOS, A. Cidade e Mobilidade. Telefones Celulares, funções pós-massivas e territórios informacionais. In: Matrizes, Revista do Programa de Pós-Graduação em Ciências da Comunicação. São Paulo, USP, ano 1, n. 1, p. 121-137, 2007.

LENHARO, R. I.; CRISTOVÃO, V. L. L.. Podcast, Participação Social e Desenvolvimento. Educação em Revista. Belo Horizonte, v.32, n.01, p. 307-335, jan-mar. 2016. 
LÉVY, P. Cibercultura. São Paulo: 34, 1999. 264 p.

LIMA, G. F. C. O discurso da sustentabilidade e suas implicações para a educação. Ambiente e Sociedade, Campinas, v. 6, n. 2, p. 99-119, 2003.

LOPES, L. Podcast - Guia Básico. Nova Iguaçu, Rio de Janeiro. Marsupial Editora. 2015.

LUIZ, L. (org.). Reflexões sobre o podcast. Marsupial, Nova Iguaçu, 2014.

LUIZ, L.; ASSIS, P. O crescimento do podcast: origem e desenvolvimento de uma mídia da cibercultura. III Simpósio Nacional ABCiber - ESPM/SP, 2009.

MEDEIROS, M. S. D. Podcasting: produção descentralizada de conteúdo sonoro. In: do XXVIII Congresso Brasileiro das Ciências da Comunicação INTERCOM, 28, 2005, Rio de Janeiro. Anais... São Paulo: Intercom, 2006. 1 CD-ROM.

MEDITSCH, E. A Rádio na era da informação: teoria e técnica do novo radiojornalismo. Coimbra, Minerva, 1999.

MUNDO PODCAST. Eco-Evolução. Podcast. Disponível em: https://mundopodcast.com.br/teiacast/ciencias/eco-evolucao-ciencia-e-educacao. Acesso em: mar. 2019.

NOVOTEMPO. Planeta Sustentável. Podcast. Disponível em: http://novotempo.com/audios/categoria/planeta-sustentavel. Acesso em: mar. 2019.

OLIVEIRA, N. R. A web 2.0 na formação docente. Livro de atas Trabalho Docente e Formação: Políticas, práticas e investigação: pontes para a mudança, p. 1291-1303, 2013.

PRATT, M. L. Os olhos do império: relatos de viagem e transculturação. Bauru: Edusc, p. 394, 1999.

PONTE, J. P. X.; LIMA, J. J. F.; RODRIGUES, R. M. Administração Municipal na Amazônia Brasileira: aspectos urbanísticos e socioambientais. Revista de Administração Municipal RAM. Instituto Brasileiro de Administração Municipal, São Paulo, n. 293, v. maio, p. 51-64, 2018. Disponível em: https://www.researchgate.net/. Acesso em: 18 dez. 2018.

PRIMO, A. F. T. Para além da emissão sonora: as interações no podcasting. In: Intexto. Porto Alegre, n. 13, 2005.

RÁDIO GREEN FM. Rotas Alternativas. Podcast. Disponível em: https://www.greenfm.com.br/category/podcast. Acesso em: mar. 2019.

RÁDIO TRANSMUNDIAL. Pensando Verde. Podcast. Disponível em: https://www.transmundial.com.br/radio/programas/pensando-verde/. Acesso em: mar. 2018. 
RÁDIO VOZES. Vozes do Planeta. Podcast. Disponível em: https://radiovozes.com/vozesdo-planeta. Acesso: mar. 2019.

REIS, A. I. O áudio invisível: uma análise ao podcast dos jornais portugueses. Revista Lusófona de Estudos Culturais/Lusophone Journal of Cultural Studies, vol. 5, n. 1, p. 209225, 2018.

RFI. Meio Ambiente. Podcast. Disponível em: https://podtail.com/podcast/meio-ambiente. Acesso em: mar. 2019.

SARKAR, T. de. Introducing podcast in library service: an analytical study. VINE Journal of Information and Knowledge Management Systems, v. 42, n. 2, p. 191-213, 2012.

SECRETARIA DO VERDE E MEIO AMBIENTE DE SÃO PAULO. Janela Verde. Podcast. Disponível em: https://soundcloud.com/janelaverdepodcast. Acesso em: mar. 2019.

SOUZA, L. Minuto da Terra. Podcast. Disponível em: https://www.listennotes.com/podcasts/minuto-da-terra-leonardo-g-de-souza-

NAXMgmnoLa3. Acesso em: mar. 2019.

STROPPER, M. T. D. Inflexão das ONGs ambientalistas após 1990: Um estudo sobre a atuação das ONGs no caso da Usina Hidrelétrica Belo Monte. 2014.

TRIGUEIRO, A. Mundo UGREEN. Eficiencialidade. Podcast. Disponível: https://www.ugreen.com.br/eficiencialidade. Acesso em: mar. 2019.

VANASSI, G. C. Podcasting como processo midiático interativo. Monografia. Caxias do Sul: Universidade de Caxias do Sul, 2007.

VEIGA, J. E. da. Cidades Imaginárias - O Brasil é menos urbano do que se calcula. Campinas: Editora da Unicamp, 2005.

VIANNA, E. Impacto Positivo. Podcast. Disponível: https://www.euricovianna.com.br/podcast-impacto-positivo. Acesso em: mar. 2019.

VOLPATO, M. Mídia Locativa, Conteúdo Geolocalizado e Reconfigurações no Jornalismo: três pistas para iniciar o debate. Parágrafo, v. 5, n. 2, p. 136-145, 2017. 